\title{
Setting Up a Flipped Classroom Design to Reduce Student Academic Procrastination
}

\author{
Dalibor Gonda ${ }^{1, *} \mathbb{1}$, Gabriela Pavlovičová ${ }^{2} \mathbb{D}$, Anna Tirpáková ${ }^{2,3}$ and Viliam Ďuriš ${ }^{2} \mathbb{C}$ \\ 1 Department of Mathematical Methods and Operations Research, Faculty of Management Science and \\ Informatics, University of Žilina, 01026 Žilina, Slovakia \\ 2 Department of Mathematics, Faculty of Natural Sciences, Constantine the Philosopher University in Nitra, \\ 94974 Nitra, Slovakia; gpavlovicova@ukf.sk (G.P.); atirpakova@ukf.sk (A.T.); vduris@ukf.sk (V.Ď.) \\ 3 Department of School Education, Faculty of Humanities, Tomas Bata University in Zlín, \\ 76001 Zlín, Czech Republic \\ * Correspondence: dalibor.gonda@fri.uniza.sk
}

Citation: Gonda, D.; Pavlovičová, G. Tirpáková, A.; Ďuriš, V. Setting Up a Flipped Classroom Design to Reduce Student Academic Procrastination. Sustainability 2021, 13, 8668. https:// doi.org/10.3390/su13158668

Academic Editor:

Enrique-Javier Díez-Gutiérrez

Received: 28 June 2021

Accepted: 28 July 2021

Published: 3 August 2021

Publisher's Note: MDPI stays neutral with regard to jurisdictional claims in published maps and institutional affiliations.

Copyright: (c) 2021 by the authors. Licensee MDPI, Basel, Switzerland. This article is an open access article distributed under the terms and conditions of the Creative Commons Attribution (CC BY) license (https:// creativecommons.org/licenses/by/ $4.0 /)$.

\begin{abstract}
The transfer of educational activities to the online environment within blended learning, which was also accelerated by the COVID-19 pandemic, increases the risk of growing student procrastination. This article describes the design of the flipped class, which is designed so that students are supported and motivated to continuously perform individual tasks. Great emphasis in the described design of the flipped classroom is placed on supporting students in their activities outside the classroom. It is in this part of blended learning that procrastination is a frequent cause of students' failure, not just in mathematics. The effectiveness of our proposed inverted class design has been experimentally verified. Statistical analysis of the data showed that students had a statistically significant reduction in procrastination behavior during the course of the experiment. The proposed flipped classroom design has the potential to increase students' self-regulatory skills, which has been reflected in a change in their approach to learning responsibilities. Students' approach to online learning outside the classroom has changed, and thus their probability of successfully completing the combinatorics course has increased statistically significantly.
\end{abstract}

Keywords: academic procrastination; inverted (flipped) class; motivation; student support; blended learning

\section{Introduction}

Current university students belong to the $\mathrm{Z}$ generation (Gen $\mathrm{Z}$ ), which is technologically advanced. They consider learning to be an activity without borders: they can learn anywhere and anytime. They prefer to use digital tools and online forums [1]. Therefore, it is not surprising to find that blended learning is currently one of the most popular and effective forms of education [2]. Blended learning can be defined as the thoughtful integration of face-to-face learning experiences in the classroom with online experiences [3]. This form of education provides students with new learning opportunities that were not previously possible [4], especially the greater use of information technology. The presence of information technologies in teaching contributes to a more intensive involvement of students in the educational process [5]. The opportunity to study outside the school environment allows the use of an inverted classroom or flipped classroom [6], which first became popular in secondary education in the United States [7]. Blended learning allows students to study outside the classroom at their own pace and at a time that suits them best. Education outside the classroom, with significant use of computer technology, also presents students with new challenges. Students are expected to have the ability to manage and conduct their studies without the direct support of the teacher, in addition to technological competencies. The absence of a teacher means testing students' own involvement in the teaching process, which is crucial in education $[8,9]$. However, research suggests 
that out-of-classroom education brings some educational freedom that will seriously test students' self-regulatory abilities. The freedom of self-paced learning offered by online forms of education always threatens students and too often leads to negative self-regulatory behavior [10-12]. Students often use the time assigned to study for other activities, which indicates their insufficient self-regulatory skills. This lack of self-regulatory ability of students very often manifests itself in the form of procrastination [13-16]. Procrastination is generally considered a psychological dysfunctional behavior [17]. This failure of selfregulation can be seen as an undesirable phenomenon that has a negative impact on the individual and also on society [18]. Not everyone is aware of the long-term negative effects of procrastination on themselves and their surroundings, and therefore, not everyone seeks help [19]. The present study focuses on the following research question:

RQ 1: To what extent is it possible to reduce the academic procrastination of undergraduate students by a suitably set flipped class design?

\section{Academic Procrastination}

Procrastination of students significantly negatively affects their learning outcomes and has a significant share in the non-completion of university studies. Unfortunately, procrastination is not an isolated phenomenon in university environments. According to research, more than $70 \%$ of university students tend to procrastinate [20]. Several studies have found that younger university students tend to procrastinate more often than older university students [21]. The transition from high school to university can be considered a critical moment. In high school, the student's learning process is largely organized by the teacher with considerable support from the student's parents. At the university level, external support is usually very limited (even in classroom learning), and therefore, young immature students may especially fail to self-regulate their learning processes and tend to fall into academic procrastination [22]. Academic procrastination most often manifests itself as a tendency to postpone the fulfillment of assigned study tasks until later, although this may have negative consequences for academic results [23,24]. Students falling into the settlements of procrastination while studying at university are only on their way to becoming fully independent adults and still need some support to successfully regulate their education [25].

Steel $[24,26]$ found in his research that three basic factors contribute to students' procrastination behavior: low probability of success in completing the task; the absence of personal benefit from the immediate performance of the task; and a large time lag between the completion of the task and the evaluation by the teacher. Grunschel, Patrzek, and Fries [27] investigated the reasons for procrastination through interviews with students. According to students, one of the factors influencing their procrastination behavior is the personality and attitude of the teacher. They cited the following characteristics of the teacher as reasons for their own procrastination: too lax approach, too high level of requirements, weak didactic competencies, and unsystematic teaching. Another important factor that contributes to the undesirable postponement of the fulfillment of study obligations is the inability of students to find adequate assistance in solving assigned tasks outside the classroom [28]. Approaches to reducing academic procrastination, which can be found in the literature, can in principle be divided into three groups: (1) therapeutic treatment, (2) therapeutic prevention, and (3) instructor/teacher intervention. The first two approaches are similar in that they use therapeutic interventions to reduce procrastination. In contrast, teacher interventions are usually very effective and easy to implement and do not require the teacher to acquire skills in specific types of therapy.

In our opinion, academic procrastination is a threat especially for those academic subjects where there is a close connection of individual knowledge. Such subjects include mathematics. Several research studies have found a significant correlation between academic procrastination and students' academic achievement in mathematics, in the sense that the higher the procrastination, the lower the success in mathematics (e.g., [29,30]). Learning mathematics, in addition to cognitive difficulty, is accompanied by affective 
effects [31]. These may be the cause of the increased rate of academic procrastination, as mathematics is associated with distress and frustration with frequent failure for students [32]. In blended learning, this frustration can be exacerbated by the absence of a teacher who could provide students with the help they need, as they generally have difficulty finding adequate self-study help [14]. The high degree of frustration at failing to solve mathematics problems then supports the deepening of academic procrastination, as people have a natural tendency to avoid tasks that they find uncomfortable and engage in activities that are more beneficial to them, especially in the short term [33]. Based on the above research, the trend of moving education to the online space is strong. This trend, accelerated by the COVID-19 pandemic, on the one hand, allows for learning anywhere and anytime and, on the other hand, carries the risk of increasing academic procrastination. Therefore, it is necessary to adapt teaching methods to the current trend of education. The design of teaching methods suitable for the implementation of combined education must be set so that, in addition to the educational function, they support the growth of students' self-regulatory abilities. Education design set up in this way has the potential to increase the success of students not only in the mathematical subjects of higher education. In order to reduce the rate of procrastination (especially in younger students), it is also necessary to focus on the position and role of the teacher in combined education, especially in the part of education outside the classroom. To reduce the high level of academic procrastination of students in the study of mathematics in the form of combined education, we have created a model for teaching a selected part of mathematics using the reverse class method. The aim of our research was to verify whether the teaching of mathematics at university by the reversed class method according to our model will contribute to the reduction of academic procrastination of students.

\section{Methodology}

\subsection{Objective}

The principle of the flipped class method is that what is usually done in the classroom, the student does at home on his/her own time and at his/her own pace, and what he/she did at home, he/she does at school under the so-called teacher supervision [34]. The flipped classroom thus consists of two components: self-study outside the classroom with the help of computer technology and time in the classroom where human interaction takes place [35]. In university courses, it is suggested that class time focus on the application of knowledge [36]. It can also give the teacher a better opportunity to spot mistakes in thinking. However, in order to fulfill this goal, it is necessary for the student to manage the domestic part of the education at the required level. We set up a flipped classroom design to have the potential to support students' positive attitudes to study, which has long-term effects on changing student behavior [37]. According to the findings of Reed et al. [38], proper design of teaching instruction can positively set students up to study mathematics. We divided the subject matter of statistical data processing into shorter parts within weekly cycles. Students always had 6 days to prepare for homework, followed by a meeting in the classroom. At the beginning of each cycle, students received complete written materials for the given combinatorial structure for study outside the classroom. The written materials contained the theoretical basis of the curriculum and control questions. We divided the written material into several short explanatory videos, which were aimed at explaining key concepts and contexts but did not cover the full range of written material. We chose short, targeted videos because research shows that students prefer shorter videos than longer videos [39]. The videos were sent to students at irregular intervals to their student email addresses and through the MS Teams application, so we tried to regularly stimulate them with the learning process. Such teacher interventions combined with the irregular provision of study material should lead to a reduction in the procrastination behavior of students [40-42].

In view of the findings of several studies $[43,44]$ that students were unable to receive adequate assistance when they did not attend class, we included other elements in the 
non-classroom section to offer space for students where they could find the help they needed. An online forum was set up where students could communicate with each other and help each other with their studies. Within the online forum, they had the opportunity to invite a teacher, who then provided them with the necessary support. Furthermore, students were given the opportunity to send questions to the teacher. The aim of learning outside the classroom was for students to achieve a conceptual understanding of basic concepts. These concepts were then the subject of applied teaching in the classroom.

Question storming took place in the classroom at the beginning of the meeting, and then the questions were answered in the form of a discussion under the supervision of the teacher. Subsequently, the subject combinatorial principle was explained and discussed using sessions to deepen the conceptual knowledge of students. In the next phase of classroom teaching, students solved various application tasks to gain a balance of conceptual and procedural knowledge in the taught issues. The activity of students in solving tasks and in the introductory discussion was continuously evaluated. This evaluation was included in the overall evaluation of students in the subject of combinatorics. At the end of the course, students took a knowledge test.

\subsection{Participants}

The experiment was carried out with the consent of the faculty management. We contacted 38 bachelor's students who repeated the combinatorics exam from the previous academic year. On a voluntary basis, 27 students participated in the research itself. As part of the research, a code was generated for each student, which ensured his/her anonymity. The connection between the code and the student was not known to the research team.

\section{Information Collection Tools}

We obtained the data needed to evaluate the research by monitoring the activity of students involved during combinatorics in the form of a flipped class. These data were obtained with the knowledge and consent of the students and were recorded anonymously. We monitored the number of views of individual videos and the number of downloads of written materials. An important source of data was also the time interval that elapsed between the availability of individual study materials and their viewing by students. We also monitored the content and form of discussions between students in the online forum. The intensity of requests for help from the teacher was also recorded. As part of the activities in the classroom, we recorded the number and content of questions within question storming by students. The point evaluations of students' activities during the solution of the tasks were carefully recorded. Since the obtained data form a sequence of comparable observations arranged with respect to time, we used time series methods to evaluate them. Specifically, we determined a mathematical function, $f(t)$, that describes the time series trend. The statistical measure of the accuracy of the estimated trend model is the coefficient of determination, which can be used to measure the adhesion of the data to the trend (regression) curve. The coefficient of determination is given by the relation

$$
R^{2}=\frac{\mathrm{S}_{\mathrm{T}}}{\mathrm{S}_{\mathrm{Y}}}=1-\frac{\mathrm{S}_{\mathrm{R}}}{\mathrm{S}_{\mathrm{Y}}}
$$

where $S_{Y}$ is the total sum of squares, which characterizes the total variability of the explained variable and is given by

$$
\mathrm{S}_{\mathrm{Y}}=\sum_{\mathrm{t}=1}^{\mathrm{n}}\left(\mathrm{y}_{\mathrm{t}}-\overline{\mathrm{y}}\right)^{2},
$$

which is a theoretical sum of squares that explains part of the variability explained by the regression model

$$
\mathrm{S}_{\mathrm{T}}=\sum_{\mathrm{t}=1}^{\mathrm{n}}\left(\overline{\mathrm{y}}_{\mathrm{t}}-\overline{\mathrm{y}}\right)^{2} \text {, }
$$


and $S_{R}$ is the residual sum of squares that represents the unexplained part of the total variability:

$$
S_{R}=\sum_{t=1}^{n}\left(y_{t}-\bar{y}_{t}\right)^{2}
$$

The coefficient of determination takes values from the interval $\langle-1,1\rangle$ and determines the part of the total variability of the observed values, which can be explained by the given regression model. In other words, after multiplying the coefficient of determination by 100, we determine what percentage of the total variability is explained by the regression model. The coefficient of determination is therefore an important characteristic of the suitability of the chosen regression model.

\section{Data Analysis and Results}

\subsection{Activities Outside the Classroom}

The basis for evaluating the effectiveness of our model of teaching combinatorics in the form of a flipped class was the activities of students outside the classroom. At the same time, they were crucial for students' activities in the classroom. The results of the recorded activities of students outside the classroom are shown in the following figures.

Figure 1 shows the gradual increase in the student's withdrawal of written materials for study. The number of downloads increases over time. We estimated the trend by linear and nonlinear functions. Based on the calculated value of the coefficient of determination $\left(R^{2}=0.8683\right)$, we can state that the nonlinear function more accurately describes the measured data. The estimated nonlinear trend is given by $7.5335 \ln (x)+8.3211$. Based on the above results, we can state that the time increase in the number of downloads does not have a natural linear course (the reliability of the linear model would be $R^{2}=0.6631$ ). We consider the cause of the non-linear increase in the number of downloads to be a suitably set design of the flipped class. We consider this trend primarily as a consequence of the content of activities taking place in the classroom. At the same time, the fact that the video recordings focused on explaining some key or problematic parts of the content of the written materials also contributed to this trend.

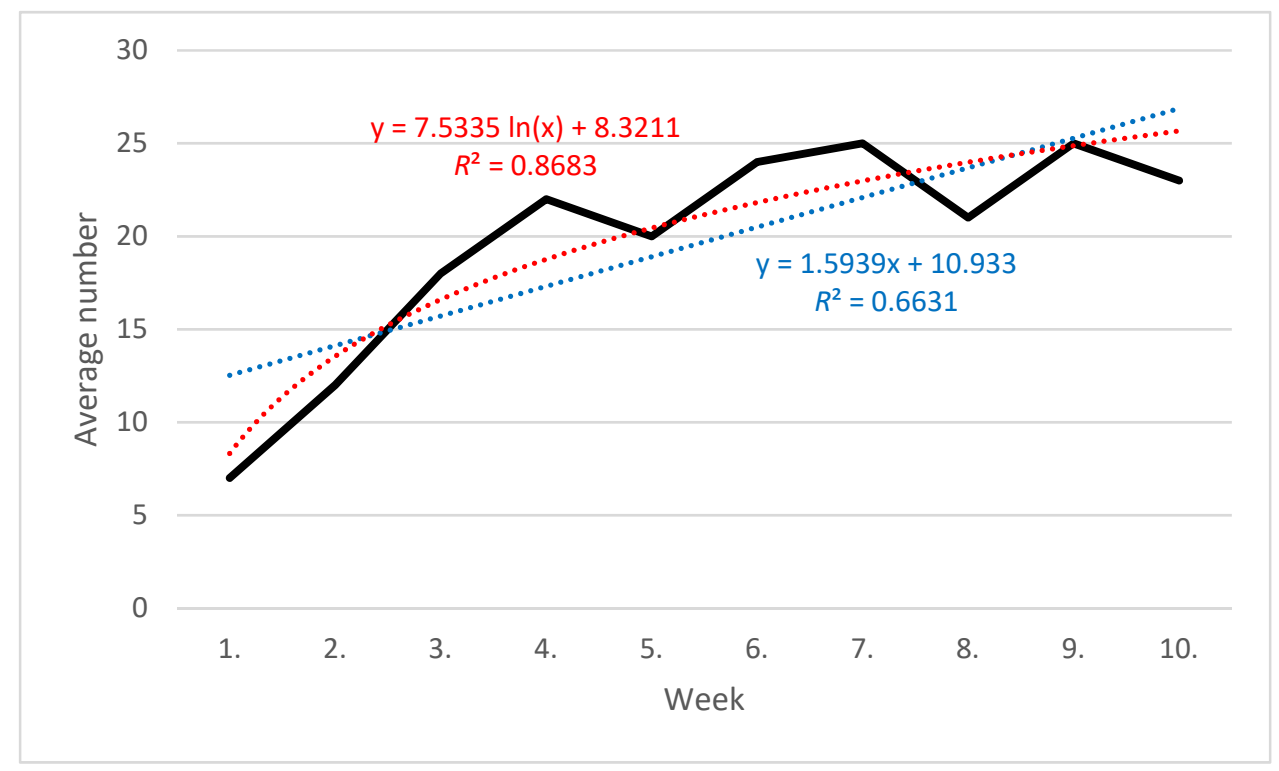

Figure 1. Average number of downloads of written documents in individual weeks.

When following the trend of other observed features (average number of hours from the availability of the video recording to its viewing; number of questions within the question storming activity; average number of points), we proceeded analogously and obtained the same results. This means that in all cases, the nonlinear function more appropriately describes the measured data in the time horizon. This again indicates that 
the temporal change in students' behavior was due to the appropriate design settings of the flipped class.

In Figure 2, we again observe the gradual decrease in the time that took place between the availability of the video and its viewing by students. According to the activity records, the students watched the videos during this period mostly shortly before the meeting in the classroom. Findings from the first weeks of the experiment suggest a last-minute postponement. Gradually, however, the time interval decreased significantly, and students devoted themselves to study duties continuously throughout the week.



Figure 2. Average number of hours from making a video available to viewing it in individual weeks.

Figure 3 shows the average student participation in an online forum set up to teach a combinatorics course, as well as the average number of questions asked by a teacher who joined an online forum after recording a question and leaving the forum after answering the question and discussing it. The rising trend in the number of questions corresponds to the gradually increasing activity of students in studying outside the classroom.

\subsection{Students' Activity in the Classroom}

We monitored the number of students' questions asked as part of the introductory question storming activity. At the same time, we monitored the number of points that students gained when solving application tasks. The results of the monitored variables are presented in Figures 4 and 5.

As part of the question storming activity, an increasing trend in the number of questions was recorded. Additionally, questions similar in content were considered to be one question. There was also an increasing trend in the number of questions in the online forum. However, the questions posed in these different activities were qualitatively different. Within the online forum, questions aimed at confirming whether the student understood the given concept or parts of the curriculum correctly prevailed. In the question storming activity, conceptual questions predominated to better understand the relationship between the new curriculum and the knowledge already acquired. There were also (from week 4) questions to explain some step of the calculation in the sample example. In the content structure of the questions, we observed a gradual shift from procedural and factual questions to conceptual ones. 


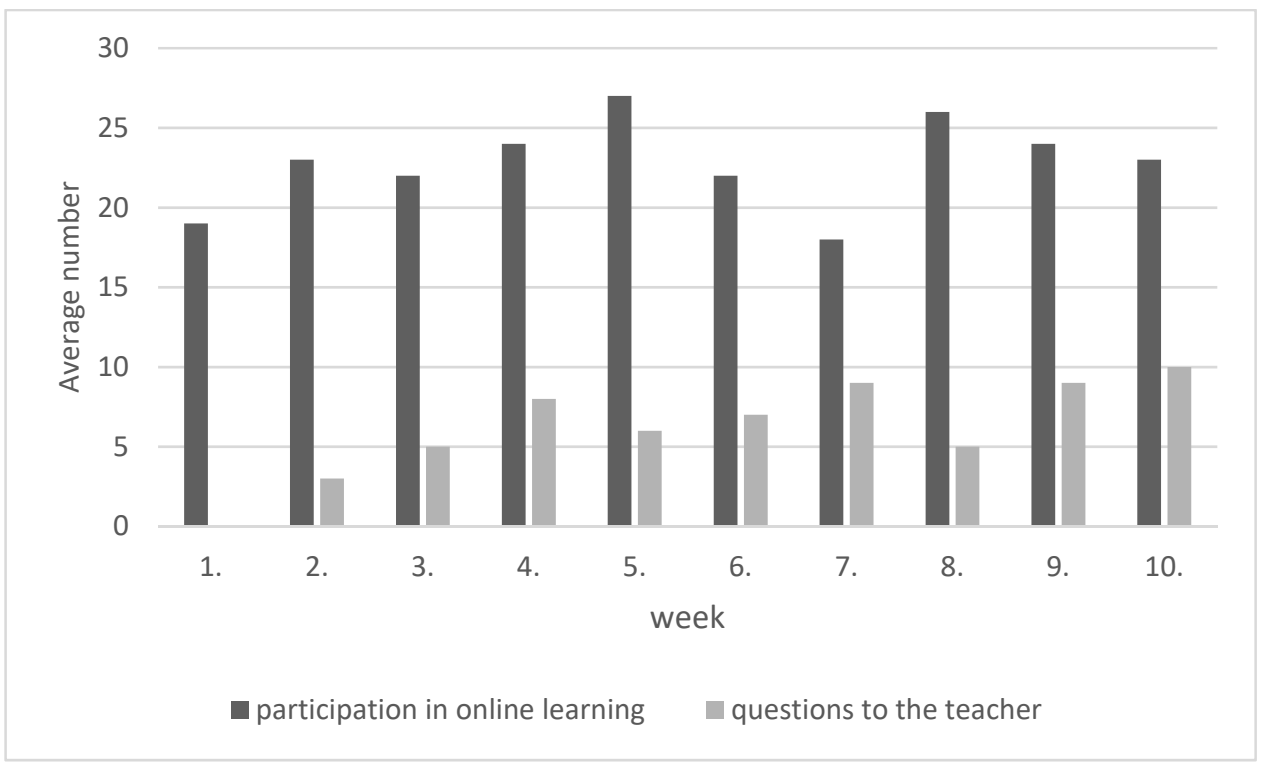

Figure 3. Student activity in the online forum for each week.



Figure 4. Number of questions within the question storming activity for each week.

The recorded rising trend corresponds to the rising quality of homework that took place in a flipped class outside the classroom. Additionally, based on activities where it was necessary to apply new knowledge from homework, it can be stated that the reduced rate of procrastination of students had a positive effect on their success in application tasks. 


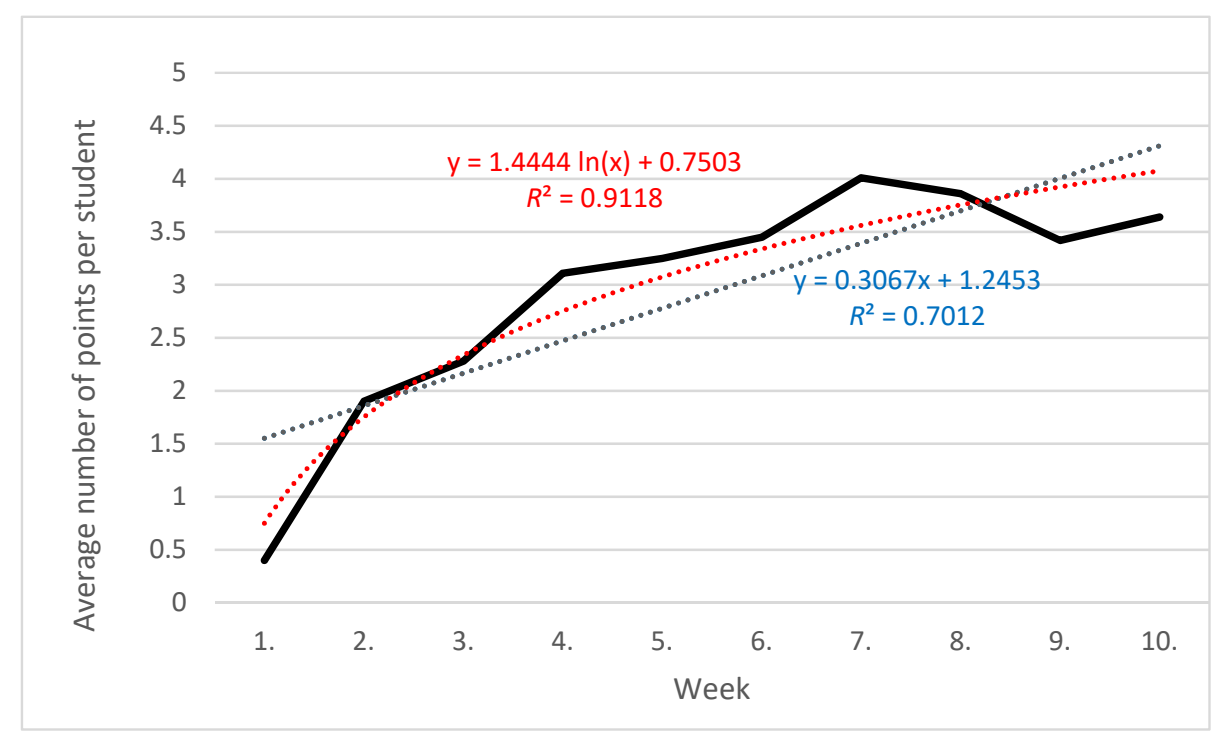

Figure 5. Average number of points per student.

\subsection{Knowledge Test}

After completing a course in combinatorics in the form of a flipped class, the students were given a test in the subject of combinatorics. We were interested in whether the students achieved better results after completing the seminar than in the previous year. We compared the test results of individual research participants with the results achieved by the same students in the subject of combinatorics in the previous academic year (before completing the course). We used the Stuart-Maxwell test to evaluate the test results before and after the seminar.

The Stuart-Maxwell test [45,46], a score-type test, is an extension of McNemar's [47] test to the situation where responses are allowed more than two response categories.

For the general matched-pair data summarized in an $r \times r$ square contingency table with total sample size $n$, we denote the probability of falling in to the $i$ th row and $j$ th column as $p_{i j}$, and we define the marginal probabilities $p_{i} .=\sum_{j=1}^{r} p_{i j}, i=1,2, \ldots, r$, and $p_{. j}=\sum_{i=1}^{r} p_{i j}, j=1,2, \ldots, r$; clearly $\sum_{i=1}^{r} \sum_{j=1}^{r} p_{i j}=1$. We usually write by using the probability table (Table 1), which is generally in the form below:

Table 1. Probability table.

\begin{tabular}{ccccc}
\hline$p_{11}$ & $p_{12}$ & $\ldots$ & $p_{1 r}$ & $p_{1 .}$ \\
$p_{21}$ & $p_{22}$ & $\ldots$ & $p_{2 r}$ & $p_{2 .}$ \\
$\vdots$ & $\vdots$ & $\vdots$ & $\vdots$ & $\vdots$ \\
$p_{r 1}$ & $p_{r 2}$ & $\ldots$ & $p_{r r}$ & $p_{r .}$ \\
\hline$p_{\cdot 1}$ & $p_{\cdot 2}$ & $\ldots$ & $p_{\cdot r}$ & 1 \\
\hline
\end{tabular}

Additionally, we denote the corresponding number of observations in the associated cases as $n_{i j}, n_{i}$, and $n_{j}$, respectively (Table 2).

Table 2. Contingency table.

\begin{tabular}{ccccc}
\hline$n_{11}$ & $n_{12}$ & $\ldots$ & $n_{1 r}$ & $n_{1}$ \\
$n_{21}$ & $n_{22}$ & $\ldots$ & $n_{2 r}$ & $n_{2 .}$ \\
$\vdots$ & $\vdots$ & $\vdots$ & $\vdots$ & $\vdots$ \\
$n_{r 1}$ & $n_{r 2}$ & $\ldots$ & $n_{r r}$ & $n_{r .}$ \\
\hline$n_{\cdot 1}$ & $n_{\cdot 2}$ & $\ldots$ & $n_{\cdot r}$ & $n$ \\
\hline
\end{tabular}

We have $n=\sum_{i=1}^{r} \sum_{j=1}^{r} n_{i j}, n_{i}=\sum_{j=1}^{r} n_{i j}, i=1,2, \ldots, r, n_{\cdot j}=\sum_{i=1}^{r} n_{i j}, j=1,2, \ldots, r$. 
To test the marginal homogeneity of the two sets of probabilities, we are interested in assessing the hypothesis $H_{0}: p_{1}=p_{1}, p_{2}=p_{2}, \ldots, p_{r}=p_{r}$.

Let $d_{i}=n_{i}-n_{i}$ for $i=1,2, \ldots, r$ and $d=\left(d_{1}, \ldots, d_{r}\right)^{\prime}$. Denote $V_{i i}=n_{i} .+n_{. i}-2 n_{i i}$, $V_{i j}=-\left(n_{i j}+n_{j i}\right)$ for $i \neq j$ and $V^{*}=\left(V_{i j}\right)_{i, j=1}^{r-1}, d^{*}=\left(d_{1}, \ldots, d_{r-1}\right)^{\prime}$. Then, if the hypothesis $H_{0}$ is true, the Stuart-Maxwell test statistics $Q=d^{* \prime} V^{*-1}, d^{*}$ are asymptotically chisquared with a degree of freedom $r-1$ for $n \rightarrow \infty$. Consequently, if $Q \geq \chi_{\alpha}^{2}(r-1)$, we reject the hypothesis $H_{0}$ at the significance level, which is asymptotically equal to $\alpha$.

In our case, we tested the null hypothesis $H_{0}$ with the Stuart-Maxwell test, which expresses that the probability of obtaining a better grade is the same before and after completing the course. We will test at a significance level of $\alpha=0.05$. The following Table 3 is contingency table for the individual grades (marks), and $Q$ is the calculated value of the Stuart-Maxwell test criterion. We will compare the value of the test criterion $\mathrm{Q}$ with the critical value $\chi_{0,05}^{2}(4)=9488$, or $\chi_{001}^{2}(4)=13.277$. We reject the tested hypothesis $H_{0}$ at the significance level $\alpha=0.05$ (or $\alpha=0.01$ ). if the value of the test criterion $Q$ is greater than or equal to the critical value 7.815 (or 13.277).

Table 3. Test results from combinatorics (in \%).

\begin{tabular}{ccccccc}
\hline \multirow{2}{*}{ Before } & \multicolumn{7}{c}{ After } & $\mathbf{5}$ & Sum \\
\cline { 2 - 7 } & $\mathbf{1}$ & $\mathbf{2}$ & $\mathbf{3}$ & $\mathbf{4}$ & $\mathbf{5}$ & $\mathbf{2}$ \\
\hline 1 & 7 & 0 & 0 & 0 & 0 & 26 \\
\hline 2 & 19 & 5 & 2 & 0 & 0 & 35 \\
\hline 3 & 12 & 19 & 5 & 0 & 0 & 28 \\
\hline 4 & 2 & 19 & 7 & 0 & 2 & 100 \\
\hline 5 & 0 & 0 & 0 & 2 & 2 &
\end{tabular}

We calculated the value of the Stuart-Maxwell test, $Q=27.268$. As the calculated value of the test criterion is greater than the critical value of 13.277, at the level of significance $\alpha=0.01$, we reject the tested hypothesis $H_{0}$, that the probability of obtaining a better grade after completing the course is different for students than the probability of obtaining a better grade before completing the course. The observed differences are statistically significant. We also showed the situation graphically (Figure 6).



Figure 6. Results of both tests from combinatorics (in \%). Source: the authors. 
Based on a graphical representation of the results of both tests (Figure 6), we can state that the probability of obtaining a better grade increased after completing the course. From Figure 6, we can see that after completing the course, the number of students (40\%) who received a grade 1 on the test increased significantly. It was only $7 \%$ for the seminar. The result of the Stuart-Maxwell test together with a graphical representation of the test results entitles us to the conclusion that by completing the course there was a positive change in students' knowledge of combinatorics. This demonstrated that the design and conceptual framework we designed for the flipped classroom was effective by reducing student procrastination.

\section{Discussion}

The flipped class is a frequently used method in combined teaching. It consists of two parts: independent work outside the classroom based on available study materials and application of knowledge gained from "homework" in solving classroom tasks. Academic procrastination is a significant threat that reduces the effectiveness of the flipped class method. The flipped class model was used for the first time for the participants of the experiment, and the recorded data from their activities prove that they underwent the process of adaptation to the new educational method. This process of adaptation was not as simple as many studies suggest (e.g., $[48,49]$ ) but required a motivational setting of the course, especially the part outside the classroom, as well as support from the teacher. Our research has confirmed that key aspects of the success of a flipped classroom include its design and conceptual framework, as well as the types and uses of specific technologies to engage students [34].

The design of our course has been set up so that students who, due to their low ability to self-regulate, postpone their study duties during the out-of-classroom phase gradually realize that their success in the classroom is conditioned by their preparation outside the classroom. At the beginning, the students were informed about this course setting, but nevertheless, the activities recorded by the students in the initial weeks of the experiment indicate a considerable degree of their procrastination. In the first week, we did not notice a single activity in up to $73 \%$ percent of them in the study outside the classroom. In the second week it was only $47 \%$. In the following weeks, all students gradually showed extracurricular activities. Thus, a gradual decline in their academic procrastination can be observed in students' behavior. We attribute this decline to two important factors. First, it is the method of teaching chosen by us in classroom meetings, where teaching was focused on application tasks, and students' activities were continuously evaluated, and the points obtained were included in the overall evaluation.

Our finding corresponds to and confirms the findings of Tuckman [50] that the regular grading of students during the course, which contributes to the overall evaluation of the course, motivates procrastinators to study continuously during the course. Students at the meeting in the classroom, in addition to points for the overall evaluation of the subject, also received immediate feedback on the current state of their knowledge. According to Cooper [51], feedback is necessary for students to understand where their knowledge needs to be improved. Our results are consistent with the research of Liu et al. [52], who demonstrated the improvement of students' learning in the use of teaching strategies with the presence of immediate feedback. The second significant factor we found to influence the gradual decrease in procrastination was the way in which video recordings were included in the course design. At the beginning of the course, our experiment confirmed that students prefer video recordings to reading written material $[53,54]$. However, the videos did not cover the entire content of the written material (as expected by the students) but formed a certain superstructure for a better understanding of the written material. This proposed change in the content of video recordings proved to be beneficial and contributed to the motivation of students to read written materials and at the same time watch video recordings. In this way, we achieved the result that students came to meetings in class better prepared than they would have been with just watching videos or just reading written 
materials, which confirms the findings of several researchers (e.g., [55]). At the same time, we succeeded in eliminating the incomplete reading tasks referred to by Sappington et al. [56]. In the study behavior of students, we recorded a process of gradual change in the approach to self-study.

This process of change took place in the first three to four weeks, where students "looked for" a way to effectively study the materials made available. At the beginning of the course, the students focused on the use of video recordings just before the meeting in the classroom, and the quality of the questions within the question storming activity testified to the focus on invoicing knowledge. This phenomenon identified by us points to the reproductive style of learning, which is preferred by students mainly at the beginning of university studies [57]. The focus of classroom meetings on the application of knowledge encouraged students to change their homework and gradually changed their homework as well as their meaning-oriented learning style [58]. This learning style requires more time for students to study, and as a result, we saw more regular activities in the extracurricular part of the course. We interpret this fact as a manifestation of a decrease in procrastination. At the same time, we observed an increase in students' own involvement in their studies, which is an important element for success in the flipped classroom [9]. We consider the identified change in students' learning style as a confirmation of the correct concept of our proposed combinatorics course, which by setting its individual components, encouraged students to think on a higher order (application tasks), which increases the likelihood of active student involvement in the learning process [59].

The presence of an online forum within the course also contributed to the acceleration of the trend of declining student procrastination behavior, where we found from the content analysis of the contributions that in the first 3 weeks, students had a mutual discussion on how to prepare for a classroom meeting. Later, mutual help and support for students in learning a new curriculum prevailed. The possibility of asking the teacher questions on an ongoing basis was also a relatively important aspect of supporting students' study activities outside the classroom. All questions asked to the teacher outside the classroom were answered in the form of a video recording, and these video recordings were made available to all course participants. The high level of viewing of videos with the teacher's answers testifies to the justification of the inclusion of this element in our concept of the flipped classroom. In this way, students were helped to overcome any obstacles associated with difficulties in understanding the new curriculum that would prevent them from continuing their homework, thus maintaining and supporting the regularity of study in the online part of the flipped classroom. At the same time, we have eliminated an undesirable fact, which is that students often seek help from unreliable and informal sources, such as various "tutorials" on various websites, in online teaching [14].

The gradually increasing number of questions per teacher was also reflected in the questions in the classroom as part of the question storming activity, where the factual questions gradually receded, as these were resolved in home training with the support of the teacher. The changed learning style and the associated lower rate of procrastination were reflected in our experiment in that students thought more about the nature of new knowledge and its connection with their already acquired knowledge; they tried to evaluate and combine individual knowledge more. Such an approach is the expression of an engaged student who has been actively involved in the learning process [60]. The results of our research revealed that the correct concept of the flipped classroom leads to the involvement of students already in activities outside the classroom. Based on the monitored variables within the activities of students at class meetings, our assumption was confirmed that application tasks will gradually encourage students to change their approach to study outside the classroom. We interpret the gradual change in students' approach to the activities within our course as a change in their internal settings. Students began to believe that learning outside the classroom could lead to success in a combinatorics course. A change in internal setting evoked by a belief in one's own ability is also reflected in a change in the way he/she learns [61]. The change in their home preparation was 
reflected in classroom meetings as the number of successful students gradually increased. A comparison of the results of the knowledge test, which the students passed after completing the course with their previous results, showed a statistically significant increase in the probability of success of the participants in the experiment in combinatorics. As one of the reasons for increased success, we identify the reduced procrastination of students, because procrastinators achieve significantly lower scores in written mathematics than non-procrastinators [62]. According to the results of our research, our proposed concept of the flipped class has the potential to reduce the academic procrastination of students and thus increase their success in mathematical subjects of university study.

In further research, we recommend identifying how it is necessary to modify the proposed design of the flipped class for application in the master's degree. According to several studies (e.g., $[54,63])$, there are differences in access to online education between undergraduate and graduate students. At the same time, we recommend that further research be devoted to the creation of study materials that would support students' conceptual acquisition of new knowledge in the preparation outside the classroom.

\section{Conclusions}

Based on our research, we can say that if we expect students to succeed in the flipped class, it is very important to direct the students' minds. The high level of academic procrastination testifies to the inappropriate study setting of students for online education. Therefore, within our concept of the flipped class, we focused on the inclusion of its individual steps so that they follow each other and encourage students to participate in all activities. For students to be successful in our course, they first had to study written materials and then watch videos explaining key points. Another important factor that influenced the success of the new concept of teaching the "flipped classroom" for students was the online forum and the opportunity to ask the teacher questions. Only quality home preparation allowed them to be successful in class meetings and continuously gain points for evaluation. Classroom assignments were chosen to give students the confidence that they could succeed in combinatorics. This changed their mindset and thus their approach to learning, as evidenced by the changing activities we observed in our experiment. Our research has also confirmed that academic procrastination can be reduced by a flipped classroom design. The necessary motivating factor leads the student to gradually realize that quality home preparation will help him/her to be successful in the subject and finds support in his/her study efforts in the concept of the flipped class.

Author Contributions: Data curation, G.P. and A.T.; Formal analysis, V.Ď.; Methodology, D.G. All authors have read and agreed to the published version of the manuscript.

Funding: This research received no external funding.

Institutional Review Board Statement: Not applicable.

Informed Consent Statement: Not applicable.

Data Availability Statement: Not applicable.

Conflicts of Interest: The authors declare no conflict of interest.

\section{References}

1. Hussin, A.A. Education 4.0 made simple: Ideas for teaching. Int. J. Educ. Lit. Stud. 2018, 6, 92-98. [CrossRef]

2. Porter, W.W.; Graham, C.R.; Spring, K.A.; Welch, K.R. Blended learning in higher education: Institutional adoption and implementation. Comput. Educ. 2014, 75, 185-195. [CrossRef]

3. Garrison, D.R.; Kanuka, H. Blended learning: Uncovering its transformative potential in higher education. Internet High. Educ. 2004, 7, 95-105. [CrossRef]

4. Lage, M.J.; Platt, G.J.; Treglia, M. Inverting the classroom: A gateway to creating an inclusive learning environment. J. Econ. Educ. 2000, 31, 30-43. [CrossRef]

5. Kontrova, L.; Lengyelfalusy, T.; Lengyelfalusyova, D. A statistical analysis of the effectiveness of selected methods in the teaching of mathematics. Commun. Sci. Lett. Univ. Zilina 2012, 14, 55-60. 
6. Lage, M.J.; Platt, G. The internet and the inverted classroom. J. Econ. Educ. 2000, 31, 11. [CrossRef]

7. Bergmann, J.; Sams, A. Remixing chemistry class: Two Colorado teachers make vodcasts of their lectures to free up class time for hands-on activities. Learn. Lead. Technol. 2009, 36, 22-27.

8. Barkley, E.F.; Major, C.H. Student Engagement Techniques: A Handbook for College Faculty; John Wiley \& Sons: Hoboken, NJ, USA, 2020.

9. Coates, H. Student Engagement in Campus-Based and Online Education: University Connections; Routledge: Philadelphia, PA, USA, 2006.

10. Chuang, H.H.; Weng, C.Y.; Chen, C.H. Which students benefit most from a flipped classroom approach to language learning? Br. J. Educ. Technol. 2018, 49, 56-68. [CrossRef]

11. Lightner, C.A.; Lightner-Laws, C.A. A blended model: Simultaneously teaching a quantitative course traditionally, online, and remotely. Interact. Learn. Environ. 2016, 24, 224-238. [CrossRef]

12. Çakıroğlu, Ü.; Öztürk, M. Flipped classroom with problem-based activities: Exploring self-regulated learning in a programming language course. J. Educ. Technol. Soc. 2017, 20, 337-349.

13. AlJarrah, A.; Thomas, M.K.; Shehab, M. Investigating temporal access in a flipped classroom: Procrastination persists. Int. J. Educ. Technol. High. Educ. 2018, 15, 1-18. [CrossRef]

14. Broadbent, J. Comparing online and blended learner's self-regulated learning strategies and academic performance. Internet High. Educ. 2017, 33, 24-32. [CrossRef]

15. Maycock, K.W.; Lambert, J.; Bane, D. Flipping learning not just content: A 4-year action research study investigating the appropriate level of flipped learning. J. Comput. Assist. Learn. 2018, 34, 661-672. [CrossRef]

16. Sun, J.C.Y.; Wu, Y.T.; Lee, W.I. The effect of the flipped classroom approach to OpenCourseWare instruction on students' self-regulation. Br. J. Educ. Technol. 2017, 48, 713-729. [CrossRef]

17. van Eerde, W.; Klingsieck, K.B. Overcoming procrastination? A meta-analysis of intervention studies. Educ. Res. Rev. 2018, 25, 73-85. [CrossRef]

18. Pychyl, T.A.; Flett, G.L. Procrastination and self-regulatory failure: An introduction to the special issue. J. Ration. Cogn. Ther. 2012, 30, 203-212. [CrossRef]

19. Stead, R.; Shanahan, M.J.; Neufeld, R.W. "I'll go to therapy, eventually": Procrastination, stress and mental health. Personal. Individ. Differ. 2010, 49, 175-180. [CrossRef]

20. Klingsieck, K.B.; Grund, A.; Schmid, S.; Fries, S. Why students procrastinate: A qualitative approach. J. Coll. Stud. Dev. 2013, 54, 397-412. [CrossRef]

21. Kim, K.R.; Seo, E.H. The relationship between procrastination and academic performance: A meta-analysis. Personal. Individ. Differ. 2015, 82, 26-33. [CrossRef]

22. Wäschle, K.; Allgaier, A.; Lachner, A.; Fink, S.; Nückles, M. Procrastination and self-efficacy: Tracing vicious and virtuous circles in self-regulated learning. Learn. Instr. 2014, 29, 103-114. [CrossRef]

23. Simpson, W.K.; Pychyl, T.A. In search of the arousal procrastinator: Investigating the relation between procrastination, arousalbased personality traits and beliefs about procrastination motivations. Personal. Individ. Differ. 2009, 47, 906-911. [CrossRef]

24. Steel, P. The nature of procrastination: A meta-analytic and theoretical review of quintessential self-regulatory failure. Psychol. Bull. 2007, 133, 65. [CrossRef] [PubMed]

25. Ferrari, J.R. Procrastination as self-regulation failure of performance: Effects of cognitive load, self-awareness, and time limits on 'working best under pressure'. Eur. J. Personal. 2001, 15, 391-406. [CrossRef]

26. Steel, P. Arousal, avoidant and decisional procrastinators: Do they exist? Personal. Individ. Differ. 2010, 48, 926-934. [CrossRef]

27. Grunschel, C.; Patrzek, J.; Fries, S. Exploring reasons and consequences of academic procrastination: An interview study. Eur. J. Psychol. Educ. 2013, 28, 841-861. [CrossRef]

28. Akçayır, G.; Akçayır, M. The flipped classroom: A review of its advantages and challenges. Comput. Educ. 2018, 126, 334-345. [CrossRef]

29. Akinsola, M.K.; Tella, A.; Tella, A. Correlates of academic procrastination and mathematics achievement of university undergraduate students. Eurasia J. Math. Sci. Technol. Educ. 2007, 3, 363-370. [CrossRef]

30. Asri, D.N.; Setyosari, P.; Hitipeuw, I.; Chusniyah, T. The influence of project-based learning strategy and self-regulated learning on academic procrastination of junior high school students' mathematics learning. Am. J. Educ. Res. 2017, 5, 88-96. [CrossRef]

31. Henschel, S.; Roick, T. Relationships of mathematics performance, control and value beliefs with cognitive and affective math anxiety. Learn. Individ. Differ. 2017, 55, 97-107. [CrossRef]

32. Asikhia, O.A. Academic Procrastination in Mathematics: Causes, Dangers and Implications of Counselling for Effective Learning. Int. Educ. Stud. 2010, 3, 205-210. [CrossRef]

33. Solomon, L.J.; Rothblum, E.D. Academic procrastination: Frequency and cognitive-behavioral correlates. J. Couns. Psychol. 1984, 31, 503. [CrossRef]

34. O'Flaherty, J.; Phillips, C. The use of flipped classrooms in higher education: A scoping review. Internet High. Educ. 2015, 25, 85-95. [CrossRef]

35. Bishop, J.L.; Verleger, M.A. The flipped classroom: A survey of the research. In Proceedings of the 120th ASEE Annual Conference \& Exposition, American Society for Engineering Education, Atlanta, GA, USA, 23-26 June 2013. 
36. Pluta, W.J.; Richards, B.F.; Mutnick, A. PBL and beyond: Trends in collaborative learning. Teach. Learn. Med. 2013, 25, S9-S16. [CrossRef] [PubMed]

37. Wilson, P. Promoting Positive Attitudes. Mathematics Teaching Incorporating Micromath. 2008. Available online: http: / / eric.ed.gov/?q=promoting+positive+attitudes\&id+EJ815090 (accessed on 1 May 2008).

38. Reed, H.C.; Drijvers, P.; Kirschner, P.A. Effects of attitudes and behaviours on learning mathematics with computer tools. Comput. Educ. 2010, 55, 1-15. [CrossRef]

39. Zappe, S.; Leicht, R.; Messner, J.; Litzinger, T.; Lee, H.W. "Flipping" the classroom to explore active learning in a large undergraduate course. In Proceedings of the ASEE Annual Conference and Exposition, American Society for Engineering Education, Austin, GA, USA, 14-17 June 2009.

40. Perrin, C.J.; Miller, N.; Haberlin, A.T.; Ivy, J.W.; Meindl, J.N.; Neef, N.A. Measuring and reducing college students'procrastination. J. Appl. Behav. Anal. 2011, 44, 463-474. [CrossRef]

41. Glomann, L.; Hager, V.; Lukas, C.A.; Berking, M. Patient-centered design of an e-mental health app. In International Conference on Applied Human Factors and Ergonomics; Springer: Cham, Switzerland, 2018; pp. 264-271.

42. Lukas, C.A.; Berking, M. Reducing procrastination using a smartphone-based treatment program: A randomized controlled pilot study. Internet Interv. 2018, 12, 83-90. [CrossRef]

43. Akçayır, M.; Dündar, H.; Akçayır, G. What makes you a digital native? Is it enough to be born after 1980? Comput. Hum. Behav. 2016, 60, 435-440. [CrossRef]

44. Chen, L.; Chen, T.L.; Chen, N.S. Students' perspectives of using cooperative learning in a flipped statistics classroom. Australas. J. Educ. Technol. 2015, 31, 621-640. [CrossRef]

45. Stuart, A. A test for homogeneity of the marginal distributions in a two-way classification. Biometrika 1955, 42, 412-416. [CrossRef]

46. Maxwell, A.E. Comparing the classification of subjects by two independent judges. Br. J. Psychiatry 1970, 116, 651-655. [CrossRef]

47. McNemar, Q. Note on the sampling error of the difference between correlated proportions or percentages. Psychometrika 1947, 12, 153-157. [CrossRef] [PubMed]

48. Mason, G.S.; Shuman, T.R.; Cook, K.E. Comparing the effectiveness of an inverted classroom to a traditional classroom in an upper-division engineering course. IEEE Trans. Educ. 2013, 56, 430-435. [CrossRef]

49. Young, T.P.; Bailey, C.J.; Guptill, M.; Thorp, A.W.; Thomas, T.L. The flipped classroom: A modality for mixed asynchronous and synchronous learning in a residency program. West. J. Emerg. Med. 2014, 15, 938. [CrossRef] [PubMed]

50. Tuckman, B.W. Using tests as an incentive to motivate procrastinators to study. J. Exp. Educ. 1998, 66, 141-147. [CrossRef]

51. Cooper, K.M.; Liddle, S.; Dascalu, S. Experiences Using Defect Checklists in Software Engineering Education. In Proceedings of the ISCA 18th International Conference on Computer Applications in Industry and Engineering, Honolulu, HI, USA, 9-11 November 2005; pp. 402-409.

52. Lidu, E.Z.F.; Laň, S.S.; Chu, C.H.; Júna, S.M. Web-besede peer review: The learner as both adapter and reviewer. IEEE Trans. Educ. 2001, 44, 246-251.

53. Toto, R.; Nguyen, H. Flipping the work design in an industrial engineering course. In Proceedings of the 2009 39th IEEE Frontiers in Education Conference, San Antonio, TX, USA, 18-21 October 2009; pp. 1-4.

54. Gonda, D.; Ďuriš, V.; Pavlovičová, G.; Tirpáková, A. Analysis of factors influencing students' Access to mathematics education in the form of MOOC. Mathematics 2020, 8, 1229. [CrossRef]

55. De Grazia, J.L.; Falconer, J.L.; Nicodemus, G.; Medlin, W. Incorporating screencasts into chemical engineering courses. In Proceedings of the 119th ASEE Annual Conference \& Exposition, San Antonio, TX, USA, 10-13 June 2012; American Society for Engineering Education: San Antonio, TX, USA; pp. 25-762.

56. Sappington, J.; Kinsey, K.; Munsayac, K. Two studies of reading compliance among college students. Teach. Psychol. 2002, 29, 272-274. [CrossRef]

57. Vermetten, Y.J.; Vermunt, J.D.; Lodewijks, H.G. A longitudinal perspective on learning strategies in higher education: Different viewpoints towards development. Br. J. Educ. Psychol. 1999, 69, 221-242. [CrossRef]

58. Boyle, E.A.; Duffy, T.; Dunleavy, K. Learning styles and academic outcome: The validity and utilityof Vermunt's inventory of learning styles in a Brittish higher education setting. Br. J. Educ. Psychol. 2003, 73, 267-290. [CrossRef]

59. Bryson, C.; Hand, L. The role of engagement in inspiring teaching and learning. Innov. Educ. Teach. Int. 2007, 44, 349-362. [CrossRef]

60. Hockings, C.; Cooke, S.; Yamashita, H.; McGinty, S.; Bowl, M. Switched off? A study of disengagement among computing students at two universities. Res. Pap. Educ. 2008, 23, 191-201. [CrossRef]

61. Blackwell, L.S.; Trzesniewski, K.H.; Dweck, C.S. Implicit theories of intelligence predict achievement across an adolescent transition: A longitudinal study and an intervention. Child Dev. 2007, 78, 246-263. [CrossRef]

62. Tice, D.M.; Baumeister, R.F. Longitudinal study of procrastination, performance, stress, and health: The costs and benefits of dawdling. Psychol. Sci. 1997, 8, 454-458. [CrossRef]

63. Aharony, N.; Bar-Ilan, J. Students' perceptions on MOOCs: An exploratory study. Interdiscip. J. E-Ski. Life Long Learn. 2016, 12, 145-162. [CrossRef] 